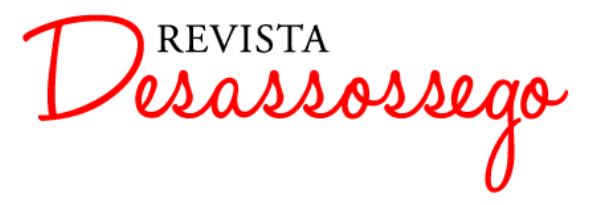

\title{
EROS EM PENA DE MULHER: O MOTIVO DA CAMA EM POEMAS DE MARIA TERESA HORTA E SALETTE TAVARES
}

\author{
CARLOS FRANCISCO DE MORAIS ${ }^{1}$
}

\begin{abstract}
RESUMO: O objetivo deste estudo é investigar como a cama se converte em um motivo literário típico da linguagem poética de duas importantes escritoras portuguesas do século XX, Maria Teresa Horta e Salette Tavares. Para isso, se observará como esse móvel, a exemplo do que acontece em textos de autores tão diversos como Safo, John Donne, Guy de Maupassant e Carlos Drummond de Andrade, se converte na escrita das duas autoras num símbolo da dimensão erótica da vida humana, entendido o erotismo como experiência essencial para a união dos opostos e a comunicação profunda entre os amantes.
\end{abstract}

PALAVRAS-CHAVE: Poesia portuguesa; poesia erótica; autoria feminina; Maria Teresa Horta; Salette Tavares.

\section{EROS IN A WOMAN'S PEN: BED AS A MOTIVE IN POEMS BY MARIA TERESA HORTA AND SALETTE TAVARES}

\begin{abstract}
This paper aims to study how the bed becomes a common literary motif in the poetic language of two important Portuguese woman writers of the $20^{\text {th }}$ century, Maria Teresa Horta and Salette Tavares. To accomplish this, it will look into how this piece of furniture, as happens in works of authors as diverse as Sappho, John Donne, Guy de Maupassant and Carlos Drummond de Andrade, manifests itself in the writings of these two poets as a symbol of the erotic dimension of human life, being eroticism seen as an essential experience to the union of contraries and to a deeper communication between lovers.
\end{abstract}

KEYWORDS: Portuguese poetry; erotic poetry; feminine authorship; Maria Teresa Horta; Salette Tavares.

Os dois temas que animam este texto, nomeadamente a autoria feminina e o erotismo, embora muito atuais no campo dos estudos literários, são ancestrais na história da poesia ocidental. Há dois milênios e meio, Safo já cantava com autoridade os prazeres do corpo a partir do ponto de vista de um sujeito poético feminino. Sua mestria sobreviveu às viragens do tempo na forma de apenas dois poemas completos, acompanhados de considerável número fragmentos dispersos em inscrições, vasos cerâmicos e textos de outros autores da antiguidade, mas não sem antes impressionar suficientemente, conforme vem na Antologia Palatina, ninguém menos que Platão, que a quis inserir no próprio cortejo de Apolo, tornando-a a décima Musa: "Some say the Muses are nine, but how carelessly!/Look at the tenth, Sappho from Lesbos" (PATTON, 1925, p. 281).

No final do século XIX, ao preparar a primeira tradução integral dos escritos sobreviventes de Safo para o inglês, Henry Thornton Warthon realça a integralidade do erotismo na obra de Safo e em sua repercussão desde a antiguidade, valendo-se para isso

\footnotetext{
${ }^{1}$ Professor Adjunto IV da Universidade Federal do Triângulo Mineiro (UFTM).
} 


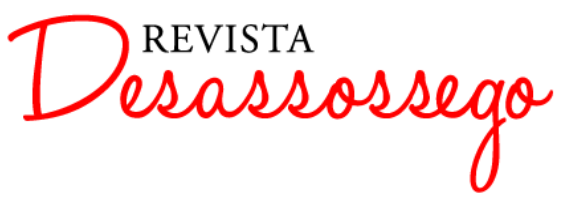

dos versos de um dos mais destacados escritores da era vitoriana, Algernon Charles Swinburne, cuja admiração por Safo era tão pronunciada que ela se converteu no principal motor de sua concepção poética, a tal ponto que nela aparece convertida realmente numa das Musas, como preconizara Platão; o trecho de Wharton que incorpora os versos referidos é este:

(...) She was on all sides regarded as the greatest erotic poet of antiquity; as Swinburne makes her sing of herself -

My blood was hot wan wine of love,

And my song's sound the sound thereof,

The sound of the delight of it. (WHARTON, 1920, p. 38)

Nos vinte e cinco séculos que nos separam da época de Safo, a poesia erótica continuou a ser cultivada por alguns dos mais importantes poetas que se conhece, associados aos mais diversos movimentos culturais, como Catulo, Filodemo, Ovídio, Petrônio, François Villon, Shakespeare, Bashô, Bocaccio, Casanova, Pierre Louÿs, Georges Bataille etc., sem que possam ser esquecidos o Kama Sutra e As mil e uma noites. Nessa longa e sempre renovada tradição, entretanto, raramente são mencionados nomes de autoras mulheres, figurando uma Louise Labbé ou uma Anaïs Nin como a exceção que confirma a regra. É tal estado de coisas que precisa ser entendido como o pano de fundo da afirmação das palavras de Maria Teresa Horta a respeito da completa novidade de sua antologia de poemas eróticos, lançada sob o título de As palavras do corpo, em 2012. Numa entrevista concedida àquela altura, a escritora portuguesa registra tanto a centralidade de Eros para a poesia quanto a predominância de pontos de vista masculinos na abordagem da temática ao longo da tradição ocidental:

\section{O erotismo é indissociável da sua poesia?}

Sim, esse peso nota-se na dimensão do livro. A sexualidade é a nossa vida. Ignorar isso é um preconceito, é tapar algo que faz parte do ser humano, do ser vivo. Se formos à poesia mais ancestral esse lado está lá. Mas falamos de uma poesia escrita por homens.

Esta é a primeira antologia de poesia erótica assinada por uma mulher?

Sim, no mundo ocidental, pelo menos, o outro não conheço tão bem. Quando o David Mourão Ferreira, de quem era muita amiga, lançou o livro Música de Cama, disse-lhe: "Lindo!" E ele respondeu: "Não, lindo será um dia a Teresa fazer uma antologia destas." Isso ficou, quase como uma promessa, a mim própria e ao meu amigo. Era um dos meus três projetos de vida. (HORTA, 2012)

Para compor As palavras do corpo, a poeta reuniu poemas de todas as épocas de sua produção, o que atesta em termos de sua prática de poesia a importância dada à dimensão 


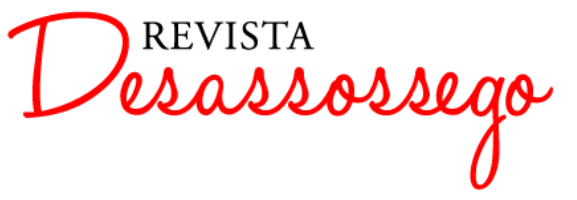

sensual do humano nos termos que usou na entrevista. É por isso que um texto da autora foi selecionado para este estudo sobre o encontro entre o erotismo e a pena feminina na literatura portuguesa, ao lado de outra escritora também do século XX que não se furtou ao tema, Salete Tavares.

Mesmo sendo razoavelmente próximas em termos de geração, pois Salete Tavares nasceu em 1922 e Maria Teresa Horta em 1937, essas autoras trilharam caminhos muito pessoais na arte, articulando estilos e mundividência particulares em sua poética. Desse modo, a integração de sua diversidade lírica dentro do ramo do erotismo é tentada nestas páginas por meio de um motivo comum a poemas das duas: a cama.

"O que se passa na cama/É segredo de quem ama", escreveu Carlos Drummond de Andrade, num dos maiores poemas de seu livro O amor natural (2013, p. 16), que é dos exemplos máximos da poesia erótica em língua portuguesa (ou qualquer outra). Assim como na pena do poeta de Itabira, também John Donne inscreve a cama em sua poesia como a sede inviolável do amor digno de ser cantado em versos:

Off with that wiry coronet and show The hairy diadem which on you doth grow: Now off with those shoes, and then safely tread In this love's hallowed temple, this soft bed. (DONNE, 1872, p. 223)

$\mathrm{Na}$ tradição lírica em língua portuguesa, a cama aparece de há muito, mesmo que apenas indiretamente, como indicam as cantigas de amigo "Sem meu amigo manh'eu senlheira", "Aquestas noites tam longas que Deus fez em grave dia" e "Da noite d'eire poderam fazer", as três dedicadas por seu autor, o trovador Juião Bolseiro (ativo em meados do século XIII na cortes de Castela e Portugal) ao tema da insônia de amor, pois que expressam a saudade e os rogos de uma mulher que está na cama sozinha, lamentando a falta de seu amado, que a leva a experimentar a própria duração da noite de maneira subjetiva, pois o tempo lhe parece passar muito mais lentamente na solidão do que acontecia quando o amigo estava presente. Também é indiretamente que o leito é referido na cantiga de Nuno Fernandez Torneol (presente nas cortes de Leão e Castela também no século XIII) cuja primeira estrofe é 'Levad', amigo, que dormides as manhanas frias/tôdalas aves do mundo d'amor dizia[m]:/leda m'and'eu." Nesta, a situação criada em torno do eu lírico feminino é aquela da mulher que está chamando o amigo amado que dorme ao seu lado na cama para que ele se vá pela manhã fria depois de ter passado a noite com ela, deixando-a com a saudade que já antecipa. 


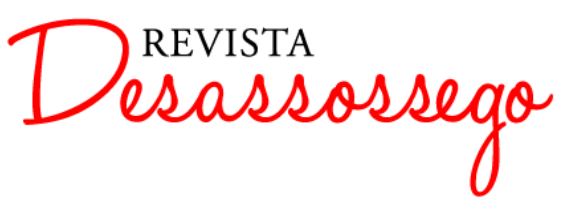

Em todos esses casos, entretanto, como é de se ver, o sujeito poético fala no feminino por meio da técnica do fingimento poético, já que a autoria é, conforme a convenção do tempo, inquestionavelmente masculina. Tal convenção para se explorar o mundo íntimo da mulher em poesia já terminara por cair por terra no século XX de Maria Teresa, Salete e Ana, abalada pelas contribuições seja da Marquesa de Alorna, seja de Florbela Espanca ou Judith Teixeira. Afigura-se, portanto, que é também pelo efeito das viragens do tempo sobre as questões sociais, políticas e educacionais que se interpunham entre os talentos de mulher e o efetivo direito ao dizer poético, que nos poemas das duas autoras selecionadas para este artigo a cama aparece diretamente nomeada, sem subterfúgios, eufemismos ou fingimentos (exceto aquele próprio do poeta, segundo Fernando Pessoa). Agindo dessa forma, as autoras começam por honrar aquela a quem os escritores da Antologia Palatina chamavam de a Décima Musa, Filha de Afrodite e Eros (WHARTON, 1920, p. 26): Safo. Num dos fragmentos de sua autoria que chegaram até nosso tempo, aqui apresentado na versão em inglês de Julia Dubnoff, o tema da despedida entre as amantes acaba por ser obscurecido, tão brilhante é a presença dos prazeres já vividos, que continuarão a existir na memória; nesse contexto, a cama é um dos símbolos mais positivos e poderosos do amor partilhado:

Honestly, I wish I were dead.

Weeping many tears, she left me and said,

"Alas, how terribly we suffer, Sappho.

I really leave you against my will."

And I answered: "Farewell, go and remember me.

You know how we cared for you.

If not, I would remind you

...of our wonderful times.

For by my side you put on

many wreaths of roses

and garlands of flowers

around your soft neck.

And with precious and royal perfume

you anointed yourself.

On soft beds you satisfied your passion.

And there was no dance,

no holy place

from which we were absent.” (SAPPHO, 2012) 


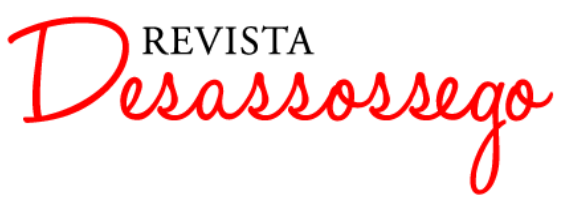

Tal como Dubnoff recriou o poema a partir do texto grego, não pode ser ocasional que o único verso a compor sozinho uma estrofe seja aquele em que a cama aparece. Observe-se que as duas estrofes que imediatamente o precedem criam uma imagem primaveril da amada aos olhos de Safo, coroando-a de rosas e circundando de guirlandas florais seu colo, que é tão suave como presumivelmente são elas, o que traz para o poema a sugestão sensorial do tato, juntamente, é claro, com as olfativas e visuais que as flores representam sem esforço. As sensações olfativas são reforçadas na próxima estrofe, na qual são lembradas não só a prática da amada de se ungir de perfumes, mas as qualidades elevadas daquele usado por ela, pois a dupla adjetivação, com "precioso" e "real", tem o condão de enfatizar não só a origem dos perfumes, mas a nobreza do momento em que era usado e de sua função no relacionamento amoroso das duas mulheres. Tais sugestões, entretanto, não completam o quadro dos "tempos maravilhosos" a que Safo aludiu antes e que deve servir de consolo depois das despedidas, pois nem as flores, nem suas cores, aromas e texturas, nem tampouco a riqueza do perfume eram capazes de, por si sós, garantir o único objetivo de qualquer paixão: a satisfação. Para isso, exclusivamente, entra em cena a cama, vista não como local de descanso, mas das ações amorosas necessárias à completude dos sentimentos, os quais, sem a expressão corpórea, não se fazem integrais no poema. O verso que diz isso está isolado no poema porque o que se passava nele isolavase, por sua importância, de tudo o mais que as amantes experimentavam na vida. Em consequência disso, a próxima estrofe, última do poema, se refere às danças e aos lugares sagrados aos quais as duas enamoradas não furtavam sua presença, trazendo para o campo do poema, portanto, tanta a dimensão artística quanto a religiosa, o que faz pensar que, no âmbito deste fragmento, não se chega às transcendências estéticas ou sacras sem passar antes pela ara do amor e prestar as devidas homenagens a Afrodite e Eros. Em Safo, então, a cama é o locus amoris por excelência, paisagem sem a qual ele não se manifesta, tal como Nikolai Abildgaard a representou numa pintura de 1809 intitulada "The Greek Poet Sappho and the Girl from Mytilene", hoje no Museu Estatal de Arte de Copenhagen; nela, a poeta é representada enquanto beija e abraça outra mulher, estando ambas reclinadas sobre um leito colocado sob uma tenda instalada em plena natureza.

Também Maria Teresa Horta escreveu poesia que coloca a cama como elemento nuclear da vivência da mulher e da expressão amorosa. São exemplos dessa prática poemas como "Mulheres", "Pequena cantiga à mulher", "Cantar à criança e à mulher", "Memorial para a história", "Retrato de uma fidalga de Lisboa", "Tua vida?”, "Poema de uma mulher 


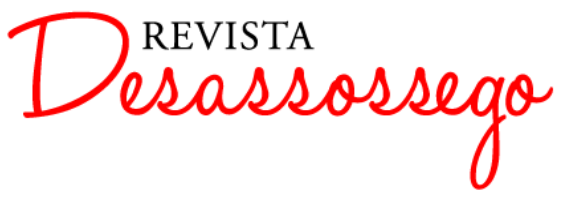

dona-de-casa", "Fim de dia de uma operária grávida", todos publicados em Poesia completa, de 1983, mesmo volume em que está o poema "Nós", que abordaremos logo em seguida a uma apresentação da autora.

Maria Teresa Horta, lisboeta nascida em 1937, jornalista de profissão, fez sua estreia literária em 1960 com o volume de poemas intitulado Espelho inicial. A ele se seguiram mais de trinta livros, entre poesia e ficção, entre os quais se destaca o succès de scandale das Novas cartas portuguesas (1972), escrito em parceria com Maria Isabel Barreno e Maria Velho da Costa, tendo as autoras passado a ser conhecidas como "As três Marias"; denunciando a repressão política e cultural da ditadura salazarista, o poder do patriarcado católico em Portugal e os problemas da época relacionados ao temas associados à condição da mulher (casamento, maternidade, sexualidade feminina), bem como as injustiças da guerra colonial movida pelo regime contra os movimentos de libertação das colônias africanas. O livro foi proibido pela censura e suas autoras processadas por imoralidade e pornografia, o que teve uma enorme repercussão internacional de condenação ao governo português, mas as escritoras só foram absolvidas depois da Revolução dos Cravos. Outra obra de destaque de Maria Teresa Horta é o romance As luz̧es de Leonor, de 2011, em que, misturando-se ficção e dados históricos, é reconstruída a história de vida, literatura, cultura e política da Marquesa de Alorna, grande nome da poesia portuguesa no Século das Luzes e tataravó da autora.

Nas últimas décadas, entretanto, o perfil público da literatura de Maria Teresa Horta tem permanecido em relativa obscuridade, como Miriam Raquel Morgante Bittencourt coloca em questão em sua tese de doutoramento sobre as dimensões erótica e política da poesia da autora:

Não é de se estranhar então porque alguém que tenha um papel tão relevante permaneça numa certa obscuridade? Por isso talvez se note a ausência de uma fortuna crítica a qual se espera de uma escritora que produziu e ainda produz obras de significante valor. Na resenha "O véu e a treva", Antonio Cabrito (1998) ao comentar o livro de poesia Destino, traça um panorama da trajetória da poesia de Horta, centrando-se, sobretudo, na presença do erotismo. Ele ressalta que há na escolha do erotismo uma coragem que não foi ainda suficientemente sinalizada. Questiona que o silêncio em torno das páginas eróticas de Horta não se daria se fossem escritas por um homem. Apesar da valorização dada às obras, o crítico afirma que “... a autora não é o grande poeta português...” (1998, p.3). Isso ainda é um fardo complicado para a mulher: não é possível aceitar que uma poetisa possa ocupar um lugar de destaque no 'Olimpo' da poesia portuguesa. (BITTENCOURT, 2005, p. 10-11) 


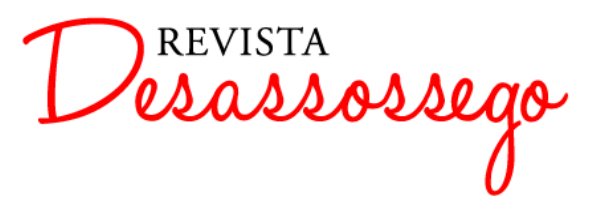

Sendo ou não admitida a um simbólico Olimpo português, fato é que a obra poética de Maria Teresa Horta já se inscreve entre as mais dignas de atenção acadêmica das produzidas desde meados do século XX. "Nós", o poema que escolhemos para avaliar a importância simbólica do motivo da cama em seu erotismo, é indicativo da altura de seu estilo.

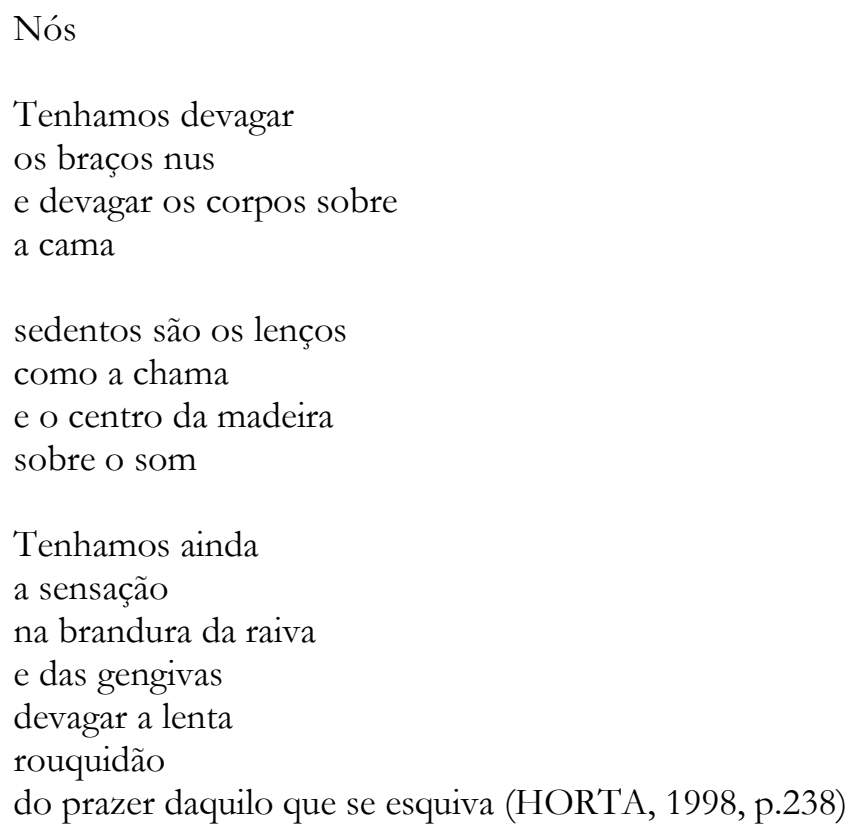

"Nós" se estrutura textualmente com base em contrastes. O que primeiro se evidencia é aquele estabelecido entre os ritmos de sua forma e de seu conteúdo. Integralmente composto por versos curtos, sendo que apenas dois deles excedem a medida do hexassílabo, o poema pode, dessa maneira, ser lido num ritmo rápido. Contrariamente a isso, os gestos, atitudes e sensações descritos ou narrados nele atendem a um ritmo lento, evidenciado na tríplice repetição do advérbio "devagar". Outro advérbio, "ainda", reforça essa construção de um ritmo lento, pois, ao surgir na quarta estrofe, traz para o poema a longa duração, que ainda permanece, da sensação antitética, à maneira de Camões, que marca os amorosos no poema: a brandura da raiva. Também é notável que o único adjetivo selecionado para a composição do texto seja "lenta", cujo sentido, em si e no uso que o poema faz dele, contrasta com a exiguidade do verso em que aparece, que se lê rapidamente na brevidade de sua redondilha menor. Também ilustra o gosto do poema pelos contrastes a proximidade espacial tanto da "rouquidão" (que nada tem de agradável em si mesma) com o "prazer", quanto deste com a esquivança atribuída à experiência que o origina. Sobre essa esquivança, é digno de nota, ainda, o fato de ser atribuída ao prazer, o 


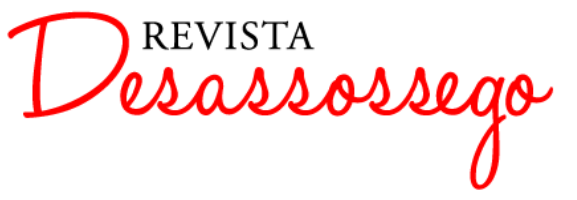

mesmo que está associado à "lenta rouquidão", de forma que nele, o prazer, se manifesta aquilo que o pensamento lógico teria muita dificuldade para entender: uma esquivança lenta.

Nem tudo no poema, contudo, é feito de contrastes. Justamente seu verso mais curto, presente logo na primeira estrofe, abre espaço para que os opostos se harmonizem. Em suas duas únicas sílabas poéticas, "a cama” propicia lugar e tempo para o amor, situado muito além das oposições que podem manter os indivíduos afastados.

Da mitologia grega, na qual se manifestava no hieros gamos (matrimônio sagrado) entre Zeus e Hera, ritualisticamente reencenado por sacerdotes e sacerdotisas para propiciar a fertilidade da terra por intermédio dos poderes de prosperidade das divindades, à Psicologia Analítica proposta por Carl Gustav Jung, a união dos opostos "é um dos princípios fundamentais da simbólica", conforme Jean Chevalier e Alain Gheerbrant (1992, p. 275). Em seu estudo sobre a utilização de diferentes recursos artísticos nos campos terapêutico, preventivo e pedagógico, com base nos postulados junguianos, Patrícia Pinna Bernardo descreve a união de opostos como uma condição necessária para o equilíbrio interno dos seres humanos, enfatizando como, nesse processo, Eros assume um papel central:

A polarização decorrente da separação do céu e da terra apresenta paralelos simbólicos com a discriminação entre a consciência e conteúdos inconscientes. Toda ampliação de consciência é sempre precedida por uma separação de opostos, sendo essa separação uma condição para podermos conhecer a realidade. Após discriminá-los, necessitamos reuni-los numa unidade, integrando o que foi apreendido aos nossos referenciais anteriores (assimilando à consciência esse novo conteúdo), o que nos confere uma visão mais abrangente da realidade assim vivenciada. Como os opostos tendem a entrar em conflito e se repelir mutuamente, como empreender então essa conjunção entre eles? Eros, como representante da energia amorosa, pode nos indicar esse caminho, pois:

Eros é um demônio, quer dizer, um intermediário entre os deuses e os homens e, como o deus do Amor está a meia distância entre uns e outros, ele preenche o vazio, tornando-se, assim, o elo que une o Todo a si mesmo (BRANDÃO, 1986, p. 187). (BERNARDO, 2007, p. 7)

No poema de Maria Teresa Horta, a cama é este lugar em que os parceiros amorosos se encontram e se igualam, convertendo-se numa metáfora de um altar erigido em honra de Eros. É nela que o plural indicado pelo título se unifica, se singulariza, pois ela se torna o espaço em que duas pessoas agem e são em uníssono. Por meio dos verbos na primeira pessoa do plural, o leitor vê, na primeira estrofe, que elas se despem juntas e dessa mesma forma ocupam a cama; na última, como experimentam juntas as sensações sincretizadas da 


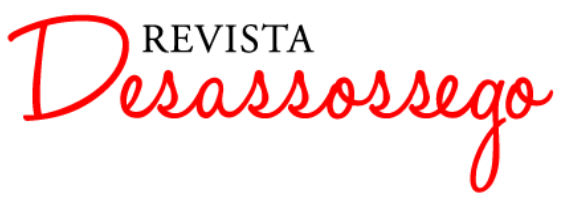

brandura e da raiva, da rouquidão e do prazer e da fuga sem pressa. Na segunda estrofe, entretanto, ponto central do poema, não há verbos, pois são desnecessários, já que a representação do desejo se manifesta por meio das imagens de sede e de fogo, bem como da sonoridade da madeira - de que é feita a cama; colocadas no ponto médio do texto, esse núcleo de sensações gustativas, táteis, visuais e sonoras serão mais facilmente entendidas se atribuídas às pessoas que sobre a cama se encontram.

Sobre a cama, as pessoas de "Nós" se encontram e se igualam, pois, pelo uso exclusivo do pronome do título e do verbo ter na primeira e terceira estrofes, torna-se impossível distinguir os amantes pelo gênero ou função dentro da parceria (assim como também não há qualquer informação sobre idades, tamanhos ou demais sinais de identificação). Nessa cama aberta para o amor no poema, tais distinções não importam nem têm lugar, tamanha a democracia que envolve as duas pessoas nesse diálogo em uníssono, o que lhes propicia a oportunidade de partilhar as sensações físicas e emocionais, em busca de um objetivo que se torna mais fácil de alcançar por meio de esforços em conjunto, ou seja, o prazer. Sendo assim, a cama, vista como um lugar de encontro, não de descanso, mas como palco das ações sob a influência de Eros, se apresenta aberta à interpretação como uma imagem essencial no fazer poético de Maria Teresa Horta, no qual o erotismo é a força motriz, como dizem suas próprias palavras, registradas na entrevista aquando do lançamento de As palavras do corpo:

Este livro reúne poemas escritos ao longo de uma vida. $\mathbf{O}$ que sente agora quando o relê?

Que sou uma mulher da sensualidade. Vejo isso através da minha escrita. Para mim, tudo tem corpo. O calor, o frio, os objetos, os sentimentos, as palavras, a escrita. O erotismo é o corpo da poesia. Cada palavra tem um corpo diferente. Sou uma colecionadora de palavras, adoro-as, tenho cadernos cheios com elas. Adoro as palavras novas que as pessoas trazem. Gosto de desencontrá-las, dar a volta ao sentido, colocar palavras num sítio onde não tinham entrada. Isso é poesia. (HORTA, 2012)

Salete Tavares também representa a cama como espaço privilegiado do amor em sua poesia.

Nascida em 1922 e com formação nas áreas de filosofia, estética e arquitetura, a escritora foi um dos nomes mais significativos no campo da poesia experimental portuguesa. Nos anos 1960, ao lado de nomes como os de António Barahona da Fonseca, António Ramos Rosa e E. M. de Melo e Castro, colaborou na revista Poesia Experimental, organizada por António Aragão e Herberto Helder no âmbito do PO-EX, sigla pela qual 


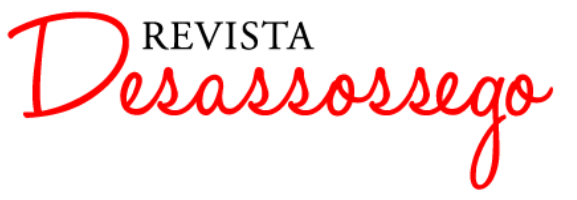

ficou conhecido o movimento da Poesia Experimental Portuguesa ou Experimentalismo Português. Uma das marcas mais fortes de sua produção é a da exploração das potencialidades expressivas da tipografia, principalmente da máquina de escrever, o que leva parte de sua obra a ser classificada como "poesia tipográfica", como registra Jorge dos Reis:

Salette Tavares é a praticante de poesia tipográfica de maior fôlego em Portugal. A maioria de seus poemas experimentais podem ser considerados poesia tipográfica, tendo em conta a solidez do uso da letra e a harmonia estética das estruturas tipográficas utilizadas nos poemas (...).

A poesia de Salette utiliza a tipografia e o espaço branco como silêncio - um silêncio mallarmeano. A sua estruturação gráfica e semântica evoca Schoenberg e o seu chanter-parler. A este propósito, escreve Luciana Stegagno Picchio:

Tavares revela o gosto sinestésico de toda vanguarda, confirma a individual propensão para a música desta artista total, plástica, verbal, audiovisual. (Picchio, 1992, p. 13) (REIS, 2010, p. 219-220)

Firmemente implantada no campo das vanguardas e dos experimentalismos, a poesia de Salette Tavares, entretanto, não é toda composta nesta vertente. Também aparecem nela os dois esteios mais visíveis da tradição lírica ocidental: o verso como meio de expressão e o amor como tema. A variedade de suportes da poética da autora é sintetizada assim por Rui Torres:

o facto de a autora nos ter deixado, a par dos livros nos quais reinventa a linguagem verbal (os de poesia substantiva e semântica, como Espelho Cego e Quadrada; ou os de poesia sobre objectos, como Lex Icon), uma considerável obra poética de características gráficas, de que fazem parte dezenas de poemas em caligrafia, tipografia e serigrafia, além de um avultado número de trabalhos de poesia espacial "fabricados" por oleiros, tecelões, e/ou relojoeiros. (TORRES, 2006, p. 267)

Quanto ao amor, seu pertencimento como temática na poesia de vanguarda de Salette Tavares pode ser exemplificado pelo poema que leva como título o tema deste artigo: "A cama", de Lex icon, de 1971. Nele, a cama é o próprio mundo entendido como casa de Eros, ou seja, lugar de atividades vitais, conforme Jean Chevalier e Alain Gheerbrant (1992, p. 376-377): “O erotismo pode revelar apenas uma espécie de desejo, até mesmo de obsessão sexual: todavia, simboliza o caráter irresistível das impulsões vitais".

A CAMA

A cama é uma piscina de lençóis onde se mergulham

corpos. 


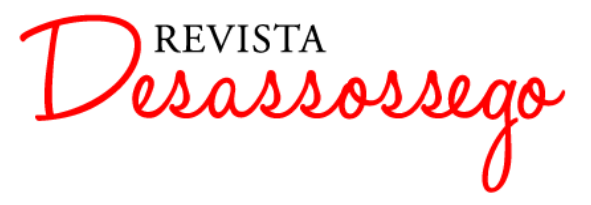

Mergulho no profundo das suas águas lisas

para dormir e amar.

Durmo submersa nos sonhos brancos e brandos

Amo liberta no destapado claro a nadar.

A cama é uma piscina de mar onde as ondas nos cobrem e descobrem onde as navegações se enterram e voam peixes no mistério.

A cama é o rio revolto das descobertas secretas do sonho e do amor. (SILVA \& BUENO, 1999, p. 123)

Tanto os claros como os cheios desse poema afirmam a importância da cama no mundo do sujeito poético que nele fala.

Em relação aos cheios, isto é, os espaços ocupados pela escrita no poema, de imediato salta à vista que três de suas estrofes trazem como primeiros versos a mesma organização de sujeito + verbo de ligação + predicativo do sujeito, destinando-se este último a apresentar sempre uma metáfora de natureza aquática para caracterizar a cama. Assim, ela passa de sólida a líquida, participando das propriedades simbólicas da água: "fonte de vida, meio de purificação, centro de regenerescência (...) representando a infinidade dos possíveis (...) as Águas que trazem vida, força e pureza, tanto no plano espiritual quanto no corporal" (CHEVALIER \& GHEERBRANT, 1992, p. 15). Essa liquefação da cama, que, em termos práticos, precisa ser sólida para suportar o peso dos corpos, é o meio encontrado pelo texto para preparar o leitor para uma interpretação dela a partir de um ponto de vista simbólico, não utilitário. Em outras palavras, é assim que se diz no poema que a cama é mais que um retângulo de madeira, pois nele passa a ser o lugar maleável para a experiência e a expressão do amor.

É a essa linha de pensamento que conduz o fato de que, de um para outro dos três versos acima aludidos, a metaforização da cama vai sendo transformada sempre na direção do simbólico, não do prático. No primeiro deles, "A cama é uma piscina de lençóis onde se mergulham", ainda há a menção à vestimenta da cama, trazendo uma sugestão ao mesmo tempo visual e tátil de algo que comunga com as camas que existem meramente no mundo dos objetos funcionais. No segundo, "A cama é uma piscina de mar", estão ausentes quaisquer menções à dimensão utilitária do móvel, já que não há nenhuma palavra do campo semântico relacionado a ele; se antes havia lençóis, agora nem eles nem travesseiros ou cobertores são nomeados; o que ocorre, em lugar disso, é a ampliação máxima de sua 


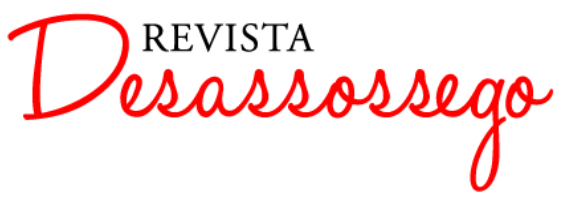

simbologia aquática, pois agora a piscina é de mar, ou seja, perdeu seus limites, sua forma definida, contida num retângulo contido noutro (o quarto), para participar da infinitude e da incontinência do mar. Neste espaço assim concebido como algo que se amplia e se supera, desconhecendo limites, abre-se a possibilidade para a experiência fundamental vivida pelo sujeito poético no início do verso central do poema: "Amo liberta", ao qual em breve voltaremos. No terceiro, "A cama é o rio revolto das descobertas secretas", a cama já é a própria vida, pois tal é o conteúdo da sua transformação metafórica em rio, que é símbolo universal da vida humana, como se vê em Chevalier e Gheerbrant (1992, p. 781): "Seja a descer as montanhas ou a percorrer sinuosas trajetórias através dos vales, escoandose nos lagos ou nos mares, o rio simboliza sempre a existência humana e o curso da vida, com a sucessão de desejos, sentimentos e intenções, e a variedade de seus desvios". Assim é que, nesse verso, a sugestão de movimento contida no adjetivo "revolto" materializa uma visão da vida humana como um percurso instável, marcado por altos e baixos, erros e acertos, tentativas, fracassos e sucessos, sempre que se direcionar, como o rio ao mar, no sentido de uma busca de suas próprias verdades e finalidades. Desta forma, ao longo das estrofes que compõem o poema, a cama vai deixando seus limites de definição como móvel, como objeto claramente definido em seus limites materiais e de utilidade para assumir o papel extraordinário de ser a própria vida de quem sobre ela coloca seu corpo, que tem uma existência tão precária quanto a da água, pois ambas se escoam, mas não sem antes marcar sua passagem. Mas é preciso se atentar para o fato de que a cama só pode fazer isso na escrita de Salette Tavares por ser nela o lugar do amor vivido nos corpos.

Quanto aos vazios do poema, ou seja, os frequentes espaços deixados em branco no interior dos versos, também eles servem à elaboração de um retrato da cama como casa de Eros.

Em todas as estrofes de "A cama" há versos em que alguma palavrasse distancia de outra por evidente decisão da poeta, já que não há qualquer razão sintática para tal acontecer. Entra aqui, portanto, o aspecto gráfico, tipográfico, espacial da escritura de Salette Tavares, que joga com a disposição das palavras de tal forma que, em lugares específicos, o espaço em branco se torna eloquente.

É o que se vê logo no início do poema, quando a frase que forma os dois primeiros versos é dividida de modo a deixar a palavra "corpos" na linha de baixo e muito distante da margem, abrindo assim um espaço em branco que chama a atenção do leitor e se abre a sua interpretação: 


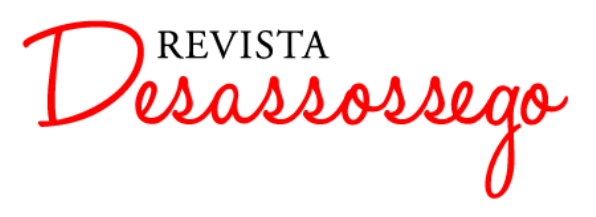

A cama é uma piscina de lençóis onde se mergulham

corpos.

O posicionamento de "corpos" no final da linha, imediatamente abaixo de "mergulham", não só mostra a diferença entre os mundos dos dois versos, pois o de baixo é habitado apenas pelos corpos, como também reproduz visualmente o movimento descendente indicado pelo verbo, simbolicamente acrescentando às duas dimensões físicas da página, altura e largura, a terceira, a da profundidade. Isso está a serviço, é de se ver, da associação da cama a uma dimensão mais profunda da vida humana, pois é nela que do sexo se chega ao erotismo, mediante a atribuição de um sentido mais que meramente epidérmico e mecânico à relação física: é o que se percebe nesses corpos que se mergulham, ou seja, se penetram, interpenetram, vão além de si, incorporando-se no outro pela força textual do pronome reflexivo, que lhes permite, mais que mergulhar apenas na cama, mergulhar um no outro. Como diria Nabokov, aqui se fala de dança, não de ginástica, pois, tal como nas formulações de Georges Bataille, Herbert Marcuse e Octavio Paz sumariadas por Bittencourt em sua tese sobre a poesia de Maria Teresa Horta, estamos levando em consideração a dimensão imaginativa, criadora, expressiva do mundo interno, do ato sexual:

A leitura do erotismo não poderia ignorar o conflito que tem marcado a relação entre amor/sexo/erotismo, já presente no pensamente do George Bataille na década de cinqüenta. Bataille procura fazer a distinção entre sexo e erotismo, conceituando o segundo como uma atividade exclusivamente humana, diferindo-o assim do instinto animal. Herbert Marcuse, por sua vez, enfatiza a questão da repressão da sociedade. $\mathrm{Na}$ análise de Marcuse, o erotismo seria fruto de uma sexualidade livre da alienação que a sociedade repressiva impõe ao sujeito. Ambos não discutem a questão do amor, tal como enfatiza Octávio Paz. Tanto sexo como erotismo são componentes essenciais do amor. Sexo é biológico e erotismo é atividade imaginativa. (BITTENCOURT, 2005, p. 8)

Ainda na primeira estrofe, o quarto verso também traz um vazio repleto de sentido:

Mergulho no profundo das suas águas lisas

para dormir e amar.

Nesse caso, a distância entre os dois verbos é a maneira encontrada pela poetisa para inserir no verso uma pausa que, numa leitura em voz alta, indicaria para a audiência a necessidade de que os dois termos sejam pensados - e pesados - separadamente. Vista a cama, já desde o início do texto, como espaço propício para se ultrapassar as superfícies das relações intercorporais, ou seja, interpessoais, agora surge às claras o sujeito poético que 


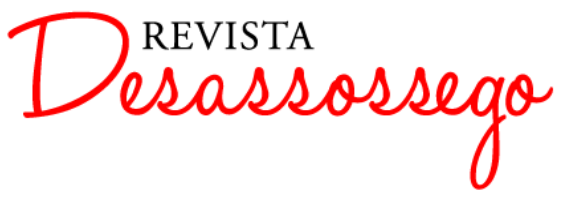

estabeleceu essa constatação como um princípio para si, já que imediatamente a pratica, como mostra o verbo na $1^{\mathrm{a}}$. Pessoa, mas tomando o cuidado de apontar as utilidades que vê na cama, lugar do sono e do amor. Entretanto, não se trata apenas de registrar as utilidades, mas de separá-las por seu valor diante da experiência que no poema interessa à voz que o articula. Dessa maneira, portanto, o espaço em branco entre "dormir" e "amar" aí está para marcar a distância que há entre os dois atos no poema, no qual dormir e amar não se confundem, pois são duas atividades distintas do corpo, ainda que realizadas sobre o mesmo móvel; isso se dá porque, em "A cama", é apenas como locus amoris que a palavratítulo interessa.

Já na segunda estrofe, há um verso com dois espaços vazios:

Durmo submersa nos sonhos brancos e brandos

Amo liberta no destapado claro a nadar.

Esse verso é o sexto dos doze que perfazem o poema, gozando, portanto, dos privilégios do centro como símbolo. Sua estruturação é muito elucidativa de tal poder, pois nele os espaços vazios separam, indicando sua identidade própria, três blocos de sentido, começando e terminando pelo principal, não só a ação praticada pelo sujeito poético na cama, ou seja, amar (de que "nadar" aqui é mais uma metáfora, na mesma linha de "mergulham", no primeiro verso), mas também a sua caracterização como um ato de liberdade, que é reforçada pelos dois adjetivos que atestam a ilimitação do espaço em que isso se dá, pois tanto quanto é líquida a cama neste poema, é também sem anteparos ou obscuridades. Assim, os dois espaços em branco servem para destacar o lugar central ocupado no verso central do poema por mais uma metáfora da cama, o "destapado claro", onde o nado livre, sem tampas, sem regras, sem disfarces, sem máscaras, é a expressão evidentemente lírica do amor.

Nas duas próximas estrofes, também há vazios nos últimos versos, mesma localização em que isso acontece nas duas primeiras. Chama a atenção, assim como o uso do espaçamento para impor uma pausa na leitura que enfatiza o sentido de cada termo isolado, o fato de que de uma para outra estrofe o espaço em branco vá diminuindo:

A cama é uma piscina de mar
onde as ondas nos cobrem e descobrem
onde as navegações se enterram e voam
peixes no mistério.

A cama é o rio revolto das descobertas secretas do sonho e do amor. 


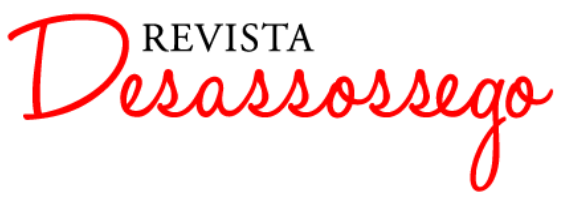

Observadas as quatro estrofes, constatamos, por meio da consulta à pagina impressa da edição que estamos utilizando, que na primeira o espaço vazio corresponde ao ocupado por 49 caracteres; na segunda, há um espaço de 19 caracteres entre as palavras que ele separa; na terceira, essa distância cai para 13 caracteres; na quarta, é apenas de sete. N' "A cama" de Salette Tavares, como no amor que ousa dizer e honrar seu nome, os espaços vão diminuindo, o que, textualmente, equivale a fazer se aproximar o sonho de sua realização, ou seja, o desejo de sua materialização corpórea. Assim, no último verso do poema, o mesmo vão que permite tanto ao "sonho" quanto ao "amor" marcarem sua individualidade também indica que o fazem em companhia um do outro, pois que ficam a uma distância sete vezes menor $(49 / 7=7)$ do que a do mergulho que os corpos precisaram dar na primeira estrofe para começar suas navegações pelas piscinas, lençóis, águas, sonhos, mares, ondas, rios e descobertas, substantivos que povoam e dão substância à cama do poema.

Ervin Goffman, considerado o mais influente sociólogo estadunidense do século $\mathrm{XX}$, costumava comentar, que "you don't really know people until you've slept with them. He felt this need, no doubt, from observing practices around him in which fellow students of society seemed only to scratch the surface of the people they studied" (HERMANOWICZ, 2002, p. 479). Absorvendo o double entendre do uso do verbo "dormir" na frase de Goffman, evidencia-se o propósito da atenção dedicada nestas páginas à presença do leito nos poemas de Salette Tavares e Maria Teresa Horta, qual seja, o de expor como não se pode verdadeiramente conhecer como na poética dessas duas mulheres se trata o tema lírico por excelência, o amor, sem ver como ele é feito na intimidade da cama. Desse modo, modestamente, aqui se procura contribuir para trazer a público como essas poetas se associam a uma longa tradição de poesia erótica centrada na cama, mas de um ponto de vista firmemente enraizado no século $\mathrm{XX}$, no qual a poesia de autoria feminina não é mais nem exceção nem mera curiosidade, mas parte do tecido coletivo da literatura.

No conto "Le lit", de Guy de Maupassant, publicado originalmente em 1882, se encontram alguns dos mais sublimes elogios à cama como lugar de encontro e símbolo da própria vida humana. Nele, o narrador, ao comprar uma casula (veste litúrgica usada por sacerdotes católicos durante a missa) do tempo de Luís XV, encontra costuradas por dentro dela quatro cartas dirigidas a um certo Abade d'Argencé; três lhe são indiferentes, pois apenas registram compromissos do religioso, mas a quarta dá todos os sinais de ter 


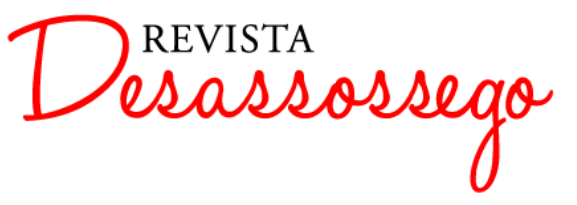

sido escrita por uma mulher, presumivelmente amante do abade. São delas as palavras sobre a cama que se seguem.

Estando acamada já há três horas, em virtude de uma indisposição, a amiga do abade passou a refletir sobre o significado do móvel para si, concluindo, logo no quarto parágrafo de sua missiva, que 'Le lit, mon ami, c'est toute notre vie. C'est là qu'on naît, c'est là qu'on aime, c'est là qu'on meurt" (MAUPASSANT, 1902, p. 77). Dessa forma, ela registra o quão essencial é a cama para todos, não só para ela, já que está presente nos momentos mais importantes da vida.

Mais adiante no conto, depois de ilustrar em maiores detalhes como a cama nos recebe na vida, ela passa a explorar a dimensão erótica do móvel, por meio destas palavras entusiasmadas sobre o primeiro encontro de dois corpos sobre um leito (mas não para dormir):

voici que pour la première fois deux amants se trouvent chair à chair dans ce tabernacle de la vie. Ils tremblent, mais transportés d'allégresse, ils se sentent délicieusement l'un près de l'autre ; et, peu à peu, leurs bouches s'approchent. Ce baiser divin les confond, ce baiser, porte du ciel terrestre, ce baiser qui chante les délices humaines, qui les promet toujours, les annonce et les devance. Et leur lit s'émeut comme une mer soulevée, ploie et murmure, semble lui-même animé, joyeux, car sur lui le délirant mystère d'amour s'accomplit. Quoi de plus suave, de plus parfait en ce monde que ces étreintes faisant de deux êtres un seul, et donnant à chacun, dans le même moment, la même pensée, la même attente et la même joie éperdue qui descend en eux comme un feu dévorant et céleste? (MAUPASSANT, 1902, p. 79).

Os tremores, os transportes, as bocas, o beijo, as delícias humanas: sobre o mar sublevado que a cama se torna pela presença dos amantes (lembrando imediatamente o "rio revolto" do poema de Salette Tavares), como se estivesse animada de alegria, dois seres se tornam um, experimentando um fogo celestial. Qual poderá ser ele, se não o de Eros em sua casa favorita? Se assim for, tornar-se-á então transparente o motivo porque, na conclusão de sua ode à cama, a amiga do abade a identifica como um símbolo da própria vida, à qual contém da melhor forma que existe no mundo: "Le lit songez-y, c'est le symbole de la vie; je me suis aperçue de cela depuis trois jours. Rien n'est excellent hors du lit” (MAUPASSANT, 1902, p. 80)

Palavras tão belas e tão definitivas sobre a importância da cama no domínio do erotismo quase nos fazem esquecer que sua autora, como mulher, é uma ficção, criada que foi dentro da obra de um autor homem, como soeu acontecer durante largas épocas da tradição literária ocidental. Aqui, entretanto, estamos dando maior relevo aos dons de Eros 


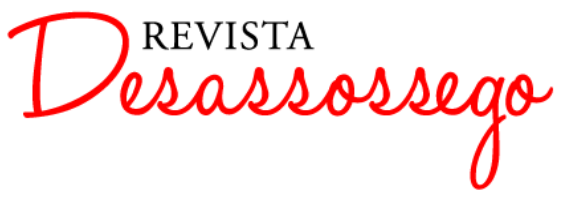

em penas de mulher, por isso, para finalizar, convém lembrarmo-nos de algumas mulheres que trilharam com Maria Teresa e Salette as sendas da poesia sobre o amor, mas sem véus, sem pudores, sem reticências, trilhas abertas por uma Safo na Antiguidade ou uma Louise Labbé (1520-1566) já ao tempo de Camões.

$\mathrm{Na}$ língua portuguesa e nestes nossos tempos pós-pessoanos, sim, mas para os objetivos deste artigo, mais corretamente descritos como pós-florbelianos, se destacam uma Hilda Hilst ou uma Ana Hatherly, em cujos versos a cama também aparece ligada ao desejo e ao prazer corpóreos. Se Louise Labé, a bela, rica e livre leonesa escreveu os versos "Tão logo sinto vir, ao me deitar,/No leito mole o sono desejado,/Meu triste espírito, de mim largado,/Incontinenti a ti vai se entregar’, de Labé (em FORTUNA, 1995, p. 186), são de Hilda Hilst (2000, p. 31) estes, na linguagem mais claramente erótica possível: "E naquela efusão... a boceta na cama... a/fartura na mesa...”. De Ana Hatherly são estes, com a cama como centro gerador de desejos e imagens poéticas:

Esta noite vou erguer-me e quando a lua vier tocar-me o rosto vou uivar como um lobo.

(...) Vou desejar a tua carne viva, os teus membros esparsos, a tua língua solta.

(...) Ah, mas a lua é uma pluma do meu leito e a lua é o colo de tu morreste para

poderes enfim tocar-me o rosto. (SILVA \& BUENO, 1999, p. 214).

Eros em pena de mulher é entendido neste estudo, portanto, como o próprio fazer poético das autoras, poetas da linhagem de Safo, artífices do jogo com a palavra pertencente à dimensão criadora, imaginativa do ser humano. Ou, como disse Maria Teresa Horta quando lhe perguntaram o que era a escrita para ela, um ato erótico:

M.J.C. - A escrita é, para si, uma catarse? Ou é, antes, um sofrimento? Lembro-me de ter dito um dia que "escrever era como um acto sexual". Ainda a entende assim?

M.T.H. - Sofrimento? Nem pensar! Eu não faço o género do escritor sofredor. Para mim, a escrita é um prazer intenso, avassalador. Não sei se será uma catarse, mas é seguramente sexual. Possui a mesma vertigem e o mesmo tipo de desejo que pulsa e empurra, excessiva, na direcção da plenitude e da queda. Escrever acelera-me o pulso, faz-me voar o coração, consciente, embora, de as todas as partes do meu corpo. (CANTINHO, 2006)

\section{REFERÊNCIAS}

ANDRADE, Carlos Drummond de. O amor natural. São Paulo: Companhia das Letras, 2013. 


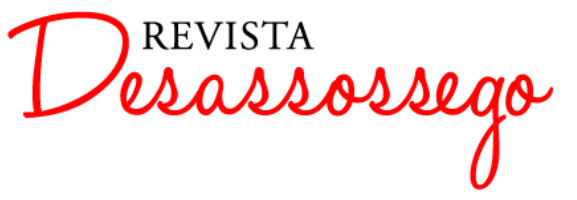

BERNARDO, P. P. "Mithohermenêutica e recursos artísticos fundamentos, alcance e aplicação dos diferentes recursos artísticos nos campos terapêutico, preventivo e pedagógico". II Colóquio de Psicologia da Arte - A correspondência das artes e a unidade dos sentidos, 2007, São Paulo. II Colóquio de Psicologia da Arte - A correspondência das artes e a unidade dos sentidos, $2007 . \quad$ Disponível em http://www.ip.usp.br/laboratorios/lapa/versaoportugues/2c57a.pdf. Acesso em 24.04.2017.

BITTENCOURT, Miriam R. M. A escrita feminina e feminista de Maria Teresa Horta. Tese de doutoramento. Faculdade de Ciências e Letras da UNESP. Assis, 2005.

CANTINHO, Maria João. “À conversa com Maria Teresa Horta”. Storm Magazine, 2006. Disponível em http://www.mariajoaocantinho.pt/news/a-conversa-com-maria-teresahorta. Acesso em 29.04.2017.

CHEVAlIER, J. \& GHEERBRANT, A. Dicionário de simbolos. Rio de Janeiro: José Olympio, 1992.

DONNE, John. The complete poems. Londres, Robson \& Sons, 1872. Disponível em https://ia601406.us.archive.org/32/items/completepoemsjo00grosgoog/completepoemsj o00grosgoog.pdf. Acesso em 19.04.2017.

FORTUNA, Felipe. Louise Labé: amor e loucura. São Paulo: Siciliano, 1995.

HERMANOWICZ, J. C. "The great interview: 25 strategies for studying people in bed". Qualitative sociology, vol. 25, n. 4, winter 2002, p. 479-499. Disponível em http://courses.washington.edu/thesis/the\%20great\%20interview.pdf. Acesso em 25.04.2017.

HILST, Hilda. Cartas de um sedutor. São Paulo: Globo, 2000.

HORTA, Maria Teresa. Destino. Lisboa: Quetzal Editores, 1998.

HORTA, Maria Teresa. “A poesia erótica de Maria Teresa Horta”. Máxima, 2012. Disponível em: http://www.maxima.pt/celebridades/detalhe/amp/maria-teresa-horta-acolecionadora-de-palavras.html. Acesso em 18.04.2017.

MAUPASSANT, Guy de. Ouevres complètes. Paris: Imprimerie Nationale, 1902. Disponível em http://www.gutenberg.org/ebooks/46470. Acesso em 26.04.2017.

PATTON, W. R. The greek anthology. Londres, William Heineman, 1925.. disponível em: https://archive.org/stream/greekanthology03pato\#page/280/mode/2up/search/sappho. Acesso em 15.04.2017. 
REIS, Jorge dos. "Salette Tavares, missionária do alfabeto. Poesia tipográfica". Estúdio. Lisboa: Faculdade de Belas-Artes da Universidade de Lisboa e Centro de Investigação e Estudos em Belas-Artes, n. 1, p. 219-227, 2010. Disponível em http://repositorio.ul.pt/bitstream/10451/3694/2/Revista\%20Estudio\%20I_Jorge\%20Rei s.pdf. Acesso em 21.04.2017.

SAPPHO. Poems of Sappho. Translated by Julia Dubnoff, 2012. Disponível em http://www.uh.edu/ cldue/texts/sappho.html. Acesso em 15.04.2017.

SILVA, A. da Costa e \& BUENO, Alexei (orgs.). Antologia da poesia portuguesa contemporânea. Rio de Janeiro: Lacerda, 1999.

TORRES, Rui. “Transposição e variação na poesia gráfica e espacial de Salette Tavares”. Aletria: Revista de Estudos de Literatura, [S.1.], v. 14, p. 266-284, dez. 2006. Disponível em: http://www.periodicos.letras.ufmg.br/index.php/aletria/article/view/1379. Acesso em: 26 abr. 2017.

WHARTON, H. T. Sappho. Memoir, text, selected renderings and a literal translation. Nova Iorque, Brentano, $1920 . \quad$ Disponível em: https://archive.org/details/sapphomemoirtex00bunngoog. Acesso em 15.04.2017. 